were women (88\%) with a mean age at diagnosis of 62 years (27-83 years), 16 Caucasians and 1 Asian. The clinical manifestations reported were: 5 myositis (29\%), 11 ILD (6 BOOP and 5 NSIP) (65\%), 6 arthritis (2 polyarthritis, 2 oligoarthritis, 1 palindromic, 1 shoulder girdle syndrome) $(35 \%), 3$ Raynaud's phenomenon (17.5\%), 2 mechanic's hands $(11 \%)$ and 6 fever (35\%). Only one patient had the classic triad (myositis, arthritis, ILD, Jo1), 2 had myositis with ILD (Jo1), 1 myositis with arthritis (PL12), 1 ILD with arthritis (PL7), 7 ILD (Jo1, PL7, PL12), 3 arthritis (Jo1), 1 RP (Jo1) and 1 fever (EJ). Ten had a nailfold capillaroscopy performed, 7 of them had any alteration: 1 active systemic sclerosis pattern and 6 nonspecific (6 ramified capillaries and 3 microhemorrhages).

Conclusion: Our immunologically defined cohort has fewer clinical manifestations than described in clinically defined cohorts (AENAS group and EuroMyositis). Only $30 \%$ of patients had myositis and $70 \%$ had a single non-myositis clinical manifestation associated with anti-ARS antibody. Actually, it involved de-novo diagnosis of AS in half of them.

In patients with suspected AS with low or negative ANA, antibody blot determination is definitive.

Nailfold capillaroscopy in undefined cases is a fundamental tool for diagnosing AS.

Disclosure of Interests: None declared

DOI: 10.1136/annrheumdis-2019-eular.4404

\section{AB0685 ACROOSTEOLYSIS AND BONE METABOLISM PARAMETERS DISTINGUISH FEMALE PATIENTS WITH LIMITED SYSTEMIC SCLEROSISWITH AND WITHOUT CALCINOSIS: A CASE CONTROL STUDY}

Marilia Sampaio-Barros, Lorena Castelo Branco, Liliam Takayama, Marco Antonio G Pontes Filho, Percival D. Sampaio-Barros, Rosa M. Pereira. Division of Rheumatology, Hospital das Clínicas da Faculdade de Medicina HCFMUSP da Universidade de São Paulo, São Paulo, Brazil

Background: Calcinosis represents a late manifestation of limited systemic sclerosis (ISSc), inducing tissue damage and chronic calcifications. Bone metabolism studies in ISSc patients are rare in literature and there are few studies that analyzed clinical, laboratory and bone mineral density (BMD) parameters together.

Objectives: The aim of this study was to compare and analyze clinical aspects and laboratory parameters, including bone metabolism variables in female ISSc patients with and without calcinosis, paired by age, disease duration and body mass index (BMI).

Methods: Thirty-six female ISSc patients with calcinosis were compared to 36 female ISSc patients without calcinosis, matched by age, disease duration and BMI. Organ involvement, autoantibodies, BMD by DXA and laboratory parameters were analyzed. The past and current treatment modalities were also questioned. Statistical significance was considered if $\mathrm{p} \leq 0.05$.

Results: Esophageal hypomotility, digital ulcers, and interstitial lung disease were the most frequent clinical manifestations of ISSc patients, present in similar frequency in both groups. Calcinosis was significantly associated with acroosteolysis $(69 \%$ vs. $22 \%, p<0.001)$, higher modified Rodnan skin score (mRSS: $4.28 \pm 4.66$ vs $1.17 \pm 2.50, p<0.001$ ), higher $25 \mathrm{OHD}(24.46 \pm 8.15$ vs. $20.80 \pm 6.60 \mathrm{ng} / \mathrm{ml}, \mathrm{p}=0.040)$ and phosphorus (3.81 \pm 0.41 vs. $3.43 \pm 0.45 \mathrm{mg} / \mathrm{dl} ; \mathrm{p}<0.001$ ) serum levels. $25 \mathrm{OHD}$ levels $>30 \mathrm{ng} / \mathrm{ml}$ were also significantly more frequent in patients with calcinosis $(p=0.041)$. ANA was positive in $89 \%$ in both groups. Anticentromere antibody was frequent (44\% and $31 \%$ ), while positive anti-Scl70 was rare in both groups. Regarding treatment, current use of corticosteroids was lower in patients with calcinosis compared to patients without calcinosis ( $8 \%$ vs. $28 \% ; \mathrm{p}=0.032)$. Osteoporosis was more frequent in the group with calcinosis $(31 \%$ vs. $17 \%)$, although not statistically significant.

Conclusion: This study showed that ISSC patients with calcinosis can present a distinct clinic and biochemical profile when compared to a matched group without calcinosis. Presence of calcinosis in female patients with ISSc can be associated with acroosteolysis and higher serum levels of 25OHD and phosphorus when compared with patients without calcinosis paired by age, disease duration and BMI.

Disclosure of Interests: MARILIA SAMPAIO-BARROS: None declared, LORENA CASTELO BRANCO: None declared, LILIAM TAKAYAMA: None declared, Marco Antonio G Pontes Filho Speakers bureau: Novartis and
Janssen, Percival D. Sampaio-Barros: None declared, Rosa M. Pereira: None declared

DOI: 10.1136/annrheumdis-2019-eular.6819

\section{AB0686 REDUCTION IN THE ABSOLUTE NUMBER OF PERIPHERAL REGULATORY T CELLS CORELATED TO CLINICAL FEATURES IN PATIENTS WITH SYSTEMIC SCLEROSIS}

Lili Shang ${ }^{1}$, Tingting Zhang ${ }^{1}$, Xiaoli Liu ${ }^{1}$, Hui Wang ${ }^{1}$, Chong Gao ${ }^{2}$, Jinfang Zhao ${ }^{3}$, LI Xiao-Feng', Huiying Gao ${ }^{1} .{ }^{1}$ The Second Hospital Of Shanxi Medical University, Rheumatology, Taiyuan, China; ${ }^{2}$ Brigham and Women's Hospital, Pathology, Boston, United States of America; ${ }^{3}$ Shanxi Medical University, Medical Statistics, Taiyuan, China

Background: The role of regulatory $T$ cells (Tregs) in the development of SSc has started being studied during the last decade with new aspects being disclosed continuously. Although there is a general agreement in the medical literature regarding the decreased functional capacity of circulating Tregs in SSc, the alteration of absolute number of Treg and Th17 cells as well as their associations with clinical characteristics of SSc are still unclear. Objectives: The present study was to investigate the relationship between multiple system impairments, disease activity and the absolute number of CD4+CD25+FOXP3+ regulatory $T$ cells (Treg cells) and Interleukin 17 producing $\mathrm{T}$ help cells (Th17) in peripheral blood of patients with systemic sclerosis (SSc).

Methods: Clinical indicators were collected from total 54 patients with SSc[8 with localized SSc (IcSSc) and 46 with diffuse SSc (dcSSc)] who were divided into two groups, mainly with skin lesions $(n=11)$ and with multiple system and organ besides skin lesions $(n=43)$. Then According to the SSc EUSTAR index, we divided 54 SSc patients into the inactive (EUSTAR $<2.5$ points, $\mathrm{n}=22$ cases) and the active group (EUSTAR score $\geq 2.5$ points, $n=32$ cases). The levels of peripheral $T$ lymphocyte were detected with flow cytometry.

Results: We found that SSc, especially dcSSc patients, had significantly fewer peripheral CD4Treg cells (both absolute number and proportion, $p<0.01)$ than healthy controls (Figure 1). In addition, the absolute number of peripheral Treg cells was significantly reduced in SSc patients with multiple system impairments $(P<0.001)$, however, the number of Th17 cells were significantly increased in SSc patients with simple skin involvement $(P=0.002)$ (Figure 2). Also the absolute number of peripheral CD4Treg cells in active group with SSc decreased more significantly, thus causing an increase in the ratio of Th17 and Treg cells (Figure 2). Conclusion: The reduced absolute number of peripheral Treg cells in SSc patients was contributed to the imbalance of Th17/Treg cells and involved in the pathogenesis of SSc, and may promote multiple system impairments and disease activity.

\section{REFERENCES}

[1] Liu M, Wu W, Sun X, et al. New insights into CD4(+) T cell abnormalities in systemic sclerosis. Cytokine Growth Factor Rev. 2016 Apr; 28:31-6. doi: 10.1016/j.cytogfr.2015.12.002.

[2] Lee GR. The Balance of Th17 versus Treg Cells in Autoimmunity. Int J Mol Sci. 2018 Mar 3;19(3). pii: E730. doi: 10.3390/ijms19030730.
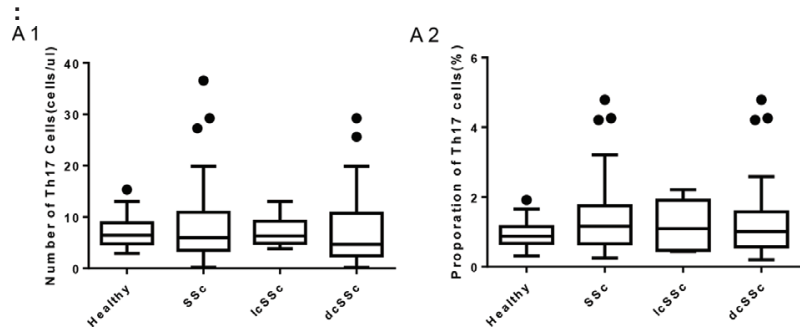

Figure 1. Absolute number of peripheral Th17 and Treg cells of patients with SSc. (A1 and A2) Neither absolute number nor proportion of Th17 cells was increased. ${ }^{*} P<0.05$; ${ }^{\star \star} P<0.01$ ${ }^{* * \star} P<0.001$. IcSSc: localized sclerosis, dcSSc: diffuse sclerosis. 